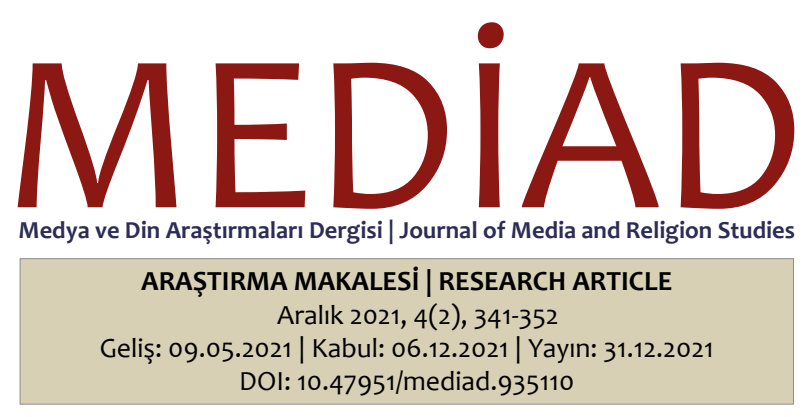

\title{
Uzaktan Din Eğitimi Hakkında Yapılan Akademik Çalıșmalar Üzerine Bir İnceleme
}

\author{
Veysel Karani ALTUN*
}

\begin{abstract}
Öz
Din eğitiminin bilimsel arenada tanınırlığını arttıran akademik çalışmalarda konu çeşitliliğinin olması alanın niteliğinin artması bakımından önemlidir. Bu çalışmanın amacı Türkiye'de din eğitiminin alt bir konusu olarak uzaktan din eğitimi hakkında akademik çalışmaları dikkate alarak bir inceleme yapmaktır. Uzaktan din eğitimi konulu kitap, tez, makale, bildiri gibi bilimsel çalışmaları; nicelik, konu dağılımı, kullanılan yöntem v.b bakımından analize tabi tutmak alanın gelişimi için önemli görülmektedir. Bu araştırma doküman incelemesi ve içerik analizine dayalı betimsel bir araştırmadır. Uzaktan din eğitimi ile ilgili olduğu belirlenen akademik çalışmaların nicelik olarak az olduğu, kapsam itibariyle dar bir yelpazeye sahip olduğu sonucuna varılmıştır. Elde edilen bulgulara göre uzaktan din eğitimi konulu akademik çalışmaların çoğunun nitel yöntemlere dayalı araştırmalardan oluştuğu tespit edilmiştir. Bu araştırma, uzaktan din eğitiminin geldiği noktayı belirleme ve bundan sonraki bilimsel çalışmalara rehberlik ederek alana katkı sunma bakımından ilk olma özelliğini taşımaktadır.
\end{abstract}

Anahtar Kelimeler: Din Eğitimi, Uzaktan Din Eğitimi, Uzaktan Din Öğretimi, Literatür Analizi

\section{A Review on Academic Studies About Distance Religious Education}

\begin{abstract}
The variety of subjects in academic studies that enhance the recognition of religious education in the scientific arena is important in terms of increasing the quality of the field. This study aims to examine by considering academic studies on distance religious education as a sub-topic of religious education in Turkey. It is significant for the development of the field to analyze scientific studies such as books, theses, articles, and papers on distance religious education in terms of quantity, subject distribution, the method used, etc. This study is descriptive research based on document review and content analysis. It has been concluded that the academic studies determined to be related to distance religious education are few in quantity and have a narrow range in scope. According to the findings, most of the academic studies on distance religious education consist of research based on qualitative methods, as well as studies based on quantitative methods. It has been found that scientific studies on distance religious education are mostly handled according to cyclical developments. This research is the first in terms of determining the current situation reached by distance religious education and contributing to the field by guiding future scientific studies.
\end{abstract}

Keywords: Religious Education, Distance Religious Education, Distance Religious Training, Literature Analysis

ATIF: Altun, V. K. (2021). Uzaktan din eğitimi hakkında yapılan akademik çalışmalar üzerine bir inceleme. Medya ve Din Araștırmaları Dergisi (MEDiAD), 4(2), s. 341-352. 


\section{Giriş}

İnsanoğlu, eğitilme ve eğitme kabiliyetleriyle donatılmış bir varlıktır. Eğitim kavramı, kişinin, belli bir alanda iyi yetişmesini veya belli bir yeti ya da melekenin bir takım araç ve yöntemlerle gelişmesini sağlayan etkinlik şeklinde tanımlanırken, kişinin, kendisini bir bütün olarak gerçekleştirmesine, insanların varlığının bütün gizil güçlerini hayata geçirmesine imkân veren süreç olarak da tarif edilmektedir (Cevizci, 1999, s. 284). Bir etkileşim sonucu gerçekleşen eğitim için süreç önemli bir husustur. Eğitim kavramına bilgi ve değer yükleme süreci şeklinde de anlam verilmiştir (Foulquie, 1994, s. 127).

Toplumlar bir süreç içerisinde gerçekleşen eğitim olgusuna her zaman önem atfetmiş, eğitimi kendi geleceği için gerekli ve önemli görmüștür. Yaşantı ürünü kalıcı izli davranış değişikliğinin gerçekleştiği öğrenme ortamlarını da önemsemişlerdir (Kılıç, 2006, s. 9; Senemoğlu, 2004, s. 88). Bunun yanında öğrenmenin klavuzlandığı öğretme faaliyetleri için devletler eliyle birbirinden farklı politikalar geliştirilmiştir (Erden, 1998, s. 20).

Dünya her alanda hızlı değişimler yaşamakta, bu değişimler teknolojinin de gelişimi ile insan hayatını yakından etkilemektedir. İnsanlık tarihine bakıldığında eğitimde sürekli bir yenileşme ve reform çabalarının olduğu görülmektedir. Özellikle öğrenme ortamlarının değişimi zamanla hız kazanmakta ve öğrenme ortamları insanların ihtiyaçları doğrultusunda şekil alabilmektedir (Varış, 1981, s. 11).

Tarihsel olarak bakıldığında eğitim ve öğretimin farklı şekillerde gerçekleştiği bilinmektedir. Daha önce eğitim, esnek sistemlerle yürütülen faaliyet olarak değerlendirilirken günümüzde eğitimin yeni iletişim teknolojilerinin etkisiyle çehresini giderek değiştirdiği görülmektedir. Bununla birlikte iletişim teknolojileri alanındaki gelişmeler insanoğlunun sosyokültürel değişimini de her zaman hızlandırmaktadır (Broadbent \& Cross, 2003, s. 23).

Yaşanan teknolojik gelişmelerle birlikte eğitim sürecinde uzaktan eğitim kavramı daha çok kullanılır olmuştur. Uzaktan eğitim teriminin ilk kez A.B.D'de Wisconsin Üniversitesi direktörü William Lighty tarafından 1906 yılında kullanıldığı bilinmektedir (Verduin \& Clark, 1994, s. 12). Bu terim 1960 ve 1970’lerde Alman eğitimci Otto Peters tarafından kullanıımış ve bu şekilde terimin kullanımı yaygınlaşmıştır (Moore, 1973, s. 661).

Mektupla eğitim, evde çalışma, dış çalışma, uzaktan öğretim, uzaktan öğrenim gibi farklı kavramlarla telaffuz edilen, öğretme ve öğrenme öğelerini bir araya getiren uzaktan eğitim için eğitim literatüründe farklı tanımlamalarda bulunulmaktadır.

Uzaktan eğitim kavramının, farklı yerlerde olan kişilerin teknolojinin yardımıyla ve iletişim araçlarının kullanımıyla özel ve sistematik şekilde öğretme ve öğrenmenin planlandığı eğitim süreci olduğu dile getirilmektedir (Moore \& Kearsley, 2005, s. 2). Holmberg'e göre uzaktan eğitim bütün öğrenme ve öğretme yöntemlerini kullanan sınıf ve okulun yönetim, planlama, rehberlik ve bunların organizasyonunu düzenleyen terimin adıdır (Holmberg, 1990, s. 5). Uzaktan eğitim kısaca, öğrenen ve öğreticinin farklı ortamlarda bulundukları sistemdir (Koşar vd., 2003, s. 20; Verduin \& Clark, 1994, s. 15).

Din, duyguları olgunlaştırma ve hayata anlam katmakla arayışta olan insanoğlu için rehberlik görevi görmektedir. Din sayesinde birey olumsuz duygularından kurtulma ve hayata olan bakışını olumlu düzeyde tutma şansı yakalar. Dinin bu özelliklerinden yararlanarak kişiye bir perspektif sunmak ise din eğitiminin ilgi alanına girmektedir (Selçuk, 1990, s. 54). Dini inancın ve dini hayatın şekillendirdiği bir hayat anlayışının eğitime konu olması bir gerçeklik olarak karşımızda durmaktadır (Yavuz, 1998, s. 54). Bu açıdan bakıldığında insanların hayata hazırlanmasında din eğitiminin önemli bir yerinin olduğu ortadadır. Din eğitimi, insanın kendisini tanımasına imkân sunan bir disiplin olarak varlığını sürdürmek ister (Armaner, 1967, s. 5). Din eğitimi aynı zamanda bireylerin ruh ve beden gelişimlerini dikkate alarak duygusal, zihinsel ve davranışsal boyutta kişiye katkı sunmak ister (Ayhan, 1997, s. 32). Din eğitiminin bu hedefleri yerine getirmeyi isterken zamanla gelişen bilim ve teknoloji ışı̆̆ında ortaya çıkan eğitim tekniklerini kullanması kaçınılmazdır. Eğitim imkânından mahrum bireyler için gelişen uzaktan eğitimin din eğitimine katacağı işlerlik önem arz etmektedir.

Kitle iletişim araçlarının öğrenme ortamları için cazip bir alternatif oluşturduğu bilinmektedir. Din eğitimi çerçevesinde düşünüldüğünde din alanındaki öğrenmelerin teknolojik gelişmeler göz ardı edilerek açıklanması mümkün değildir (Furat, 2019, s. 30).

Türkiye'de uzaktan din eğitimi tarihi serüvenine bakıldığında uzaktan din eğitimi politikalarının uzaktan eğitim politikaları ile birlikte değerlendirildiğini görmekteyiz. 1975 yılında İmam Hatip Okulu çıkışıları öğretmen olarak yetiştirmek için Yüksek İslam Enstitüleri bünyesinde dışarıdan bitirme programı düzenlenmiştir (Kaya, 2002, s. 32). Bu program kısa süre sonra sonlandırılınca ülkede uzaktan din eğitimi politikaları mevcut 
uzaktan eğitim politikaları içerisine dâhil edilmiştir (Karateke, 2020, s. 43). Bu tarihten sonra Açı Öğretim İmam Hatip Liseleri ve yükseköğretim düzeyinde ilahiyat Ön Lisans Programları ile ilahiyat Lisans Tamamlama Programları açılmıştır.

2002 yılında Ankara Üniversitesi'nde kurulan Uzaktan Eğitim Merkezi (ANKUZEM) bünyesinde 2005 yılında Illahiyat Lisans Tamamlama (iLiTAM) ilahiyat Fakültesi akademik koordinatörlüğünde faaliyete başlamıştır (Altaş, 2016, s. 17).

Mesleki açık öğretim lisesi kapsamında din içerikli birçok dersin uzaktan eğitimi verilmektedir. Lise öğrenimini bitiren bir öğrenci ILITAM adı verilen önlisans veya lisans tamamlama programlarıla eğitimini bitirebilmekte ve yüz yüze eğitim gören öğrencilerle aynı haklara sahip olarak mezun olabilmektedir (Gözütok, 2013, s. 29).

Zamanla maliyet açısından düşünüldüğünde uzaktan eğitim yoluyla eğitimin yaygınlaşacağı ve daha kısa sürede gerçekleşeceği beklense de bu durumda uzaktan eğitimin, eğitimin gerçek işlevini yerini getirip getirmeyeceği hususu tartışılmaya başlanmıştır. Yüz yüze eğitim ile karşılaştırıldığında uzaktan eğitimin mekân ve zaman açısından bilgiye ulaşma noktasında insana kolaylık sağladığı görülse de bilgiyi anlama ve içselleştirmedeki işlevselliği merak konusu olmuştur. Mesele din eğitimi çerçevesinde düşünüldüğünde bu merak daha da artmaktadır. Tam da bu noktada uzaktan din eğitim hakkında yapılan akademik çalısmaların ortaya çıkarılması önem kazanmaktadır.

Din eğitimi konulu bilimsel çalışmalar hakkında yapılan literatür incelemelerine rastlamak mümkündür. Yapılan incelemelere genel olarak din eğitiminin bugüne kadarki yayınlarına nicelik, konu ve yöntem açısından yer verilmiştir (Aşıkoğlu, 1994; Kayadibi vd., 2008; Kaymakcan \& Unsal, 2004; Kızılabdullah, 2009; Öcal, 2008; Tosun, 2009). Uzaktan din eğitimi hakkında literatür incelemesine ise rastlanmamıştır. Bu çalışmanın uzaktan din eğitimi hakkında yapılan ilk literatür incelemesi olması alandaki önemli bir boşluğun giderilmesi açısından kayda değerdir.

Bu çalışma doküman incelemesi yöntemi ile gerçekleştirilmiştir. Doküman incelemesi, gözlem veya görüşme yapmanın zor olduğu durumlarda tek başına araştırma yöntemi olarak kullanılabilmektedir. Doküman incelemesinde amaç, dokümanların ayrıntılı bir biçimde analiz edilmesidir (H. Şimşek \& Yıldırım, 2008). Ayrıca bu çalışma veriler arasındaki ilişkileri istatiksel olarak ortaya koyması açısından nicel yöntemi de kullanan bir çalışmadır. Uzaktan din eğitimi konulu akademik çalışmalar konu, içerik, yöntem gibi çeşitli açılardan tasnif edilmiştir. Elde edilen veriler bu sınıflandırmaya göre analiz edilmiştir.

\section{Uzaktan Din Eğitimi Hakkında Yapılan Bilimsel Çalıșmalar}

Din eğitimi bilimsel biri disiplin olarak yeni sayılabilecek bir alandır. 1980 yılında Ankara Üniversitesi ilahiyat Fakültesinde akademik bir kürsü olarak kurulan ve bu tarihten sonra bilimsel arenada varlığını hissettiren din eğitimi disiplininin bu yolda hızla mesafe aldığı görülmektedir (Aşıkoğlu, 1994, s. 88; Kızılabdullah, 2009, s. 309). Din eğitimi her ne kadar 1980 yılında bilimsel bir disiplin haline geldiği görülse din eğitimi konulu akademik çalışmalara daha önceki yıllarda da rastlamak mümkündür. Din eğitimi hakkında yapılan bilimsel çalışmaların pek çok alt konu başlı̆̆ı altında incelendiği görülmektedir. 2005 yılında Ankara Üniversitesi Uzaktan Eğitim Merkezi bünyesinde açılan ILITAM ile birlikte uzaktan din eğitimi konulu bilimsel çalışmaların da yapılmaya başlandığı görülmektedir.

Uzaktan din eğitimi hakkında kitap, makale, bildiri, tez v.b bilimsel çalışmaların sayıca çok az olduğu belirlenmiştir. Bu araştırma 2021 yılı Ekim ayına kadar yayımlanan akademik çalışmalarla sınırlıdır. Uzaktan din eğitimi konulu 40 bilimsel çalışmaya ulaşılmıştır. Bunlardan 2'si kitap, 27'si makale, 5'i bildiri, 1'i doktora tezi ve 5'i yüksek lisans tezidir. Uzaktan din eğitimi hakkında yapılan bilimsel çalışmalar alfabetik olarak şunlardır:

- Akaslan, Y. (2020). Mahiyet, Nitelik Ve Müfredat Açısından ilitam Programlarında Kur'an-ı Kerim Dersleri (Ondokuz Mayıs Üniversitesi Örneği). Ondokuz Mayıs Üniversitesi Illahiyat Fakültesi Dergisi, 49, 9-37.

- Akman, A. (2021). Illköğretim Din Kültürü ve Ahlak Bilgisi Öğretmenlerinin Uzaktan Eğitime Yönelik Tutumları [Yüksek Lisans Tezi]. Necmeddin Erbakan Üniversitesi Sosyal Bilimler Enstitüsü.

- Altaş, N. (2016). Türkiye'de Dinî Yükseköğretim Alanında Uzaktan Eğitimle ilgili Algı Sorunları Ve ilitam Uygulamaları. Değerler Eğitimi Dergisi, 14(31), 7-41.

- Altaş, N. (2015). Uzaktan Eğitim Ve ilitam Uygulamalarının Geleceği Nasıl Olmalıdır. Bugünün İlahiyatı Nasıl Olmalıdır? (Sorunlar ve Çözümler), 387-412.

- Altun, V. K. (2021). Covid-19 Pandemi Sürecinde Din Kültürü ve Ahlak Bilgisi Öğretmenlerinin Uzaktan 
Eğitim İle İlgili Görüşlerinin Değerlendirilmesi. Turkish Studies-Educational Sciences, 16(5), 2127-2145.

- Arslan, F., \& Korkmaz, Ö. (2019). Illahiyat Lisans Tamamlama Uzaktan Eğitim Öğrencilerinin Etkileşim Kaygıları Ve Uzaktan Eğitime Dönük Tutumları. Ahmet Keleşoğlu Eğitim Fakültesi Dergisi, 1(1), 12-25.

- Aydın, Y., Karasu, T., \& Ülger, E. (2021). Yüksek Öğretiminde Uzaktan Eğitimin İmkânı Ve Karşılaşılan Problemler: Muş Alparslan Üniversitesi İslami illimler Fakültesi Örneği. Anemon Muş Alparslan Üniversitesi Sosyal Bilimler Dergisi, 9(4), 1141-1158.

- Başkonak, M., \& Akşener, A. (2020). Kuran Öğretiminde Yeni Yaklaşımlar: On Saatte Online Kuran Eğitimi Örneği. Şırnak Üniversitesi Illahiyat Fakültesi Dergisi, 11(25), 714-740.

- Bayraktutan, T. A. (2021). Illahiyat Lisans Tamamlama (ilitam) Programına iliş̧kin Öğrencï Görüșlerï (Sivas Cumhuriyet Üniversitesi Örneği) [Yüksek Lisans Tezi]. Sivas Cumhuriyet Üniversitesi Sosyal Bilimler Enstitüsü.

- Becit İşçitürk, G., \& Turan, E. Z. (2018). Din Kültürü Ve Ahlak Bilgisi Öğretmenlerinin Eğitim Bilişim Ağına iliş̧kin Görüşlerï. Electronic Turkish Studies, 13(29), 35-45.

- Birinci, K. (2010). Uzaktan Eğitim ve Din Öğretiminde Bir Uygulama Örneği: İlahiyat Lisans Tamamlama (ilitam) [Yüksek Lisans Tezi]. Ankara Üniversitesi Sosyal Bilimler Enstitüsü.

- Çakmak, A., \& Uzunpolat, Y. (2021). Din Kültürü Ve Ahlak Bilgisi Öğretmenlerine Göre Salgın Döneminde Uzaktan Eğitim. Tasavvur/Tekirdağ ilahiyat Dergisi, 7(1), 855-892.

- Çıtırık, A. N., \& Zengin, Z. S. (2020). Küresel Salgın Zamanında Din Görevlileri Gözüyle Diyanet İşleri Başkanlığı'nın Yaygın Din Hizmeti Ve Eğitimi. Yüzüncü Yıl Üniversitesi Sosyal Bilimler Enstitüsü Dergisi, Salgın Hastalıklar Özel Sayısı, 599-624.

- Dağ, M. (2013). İlahiyat Lisans Tamamlama (ilitam) Programlarında Kur'an Dersï. Ekev Akademi Dergisi, 55, 37-54.

- Erdoğan, İ. (2021). Covï-19 Pandemisi Sürecinde Uzaktan Eğitim Ve İlahiyat Fakültesi Öğrencilerinde Akademik Dürüstlük. Iç̧inde M. Okumuşlar, Z. Çiftçi, \& S. Bayrakçı (Ed.), Olağan Dışı Dönemlerde Ahlak ve Vicdan Ekseninde Değişim, Süreklilik ve Sürdürülebilirlik (C. 2, ss. 273-307). Timav Yay.

- Erken, B. (2016). Online İslamï Eğitim: Qibla.com Örneği [Yüksek Lisans Tezi]. Marmara Üniversitesi Sosyal Bilimler Enstitüsü.

- Erpay, İ. (2021). Zorunlu Uzaktan Eğitim: Covid-19 Pandemisi Sürecinde İlahiyat Öğrencilerinin Uzaktan Eğitime Yönelik Görüşleri. Marifetname, 8(1), 169-204.

- Furat, A. Z. (2019). Din Eğitimi Ekseninde Türkiye'de Medya Ve Din Araştırmaları. Medya ve Din Araştırmaları Dergisi, 2(1), 29-51.

- Genç, M. F., Ay, M. F., \& Gümrükçüoğlu, S. (2021). Koronavïrüs (covid-19) Sürecïnde illahïyat Alanında Lïsansüstü Eğitïm Gören Öğrencïlerïn Uzaktan Eğitïme Bakışları. Dinbilimleri Akademik Araştırma Dergisi, 21(1), 71-97.

- Genç, M. F., \& Ayhan, M. (2007). İlitam Bölümü Öğrencilerinin Hadis Dersine Yönelik Tutumları. Mizanü'l-Hak: İslami ilimler Dergisi, 12, 77-109.

- Genç, M. F., \& Gümrükçüoğlu, S. (2020). Koronavirüs (covıd-19) Sürecinde illâhiyat Fakültesi Öğrencilerinin Uzaktan Eğitime Bakışları. Electronic Turkish Studies, 15(4), 403-422.

- Gözütok, Ş. (2013). E-öğrenme ve Yeni Öğrenme Ortamları. İçinde H. Aydın \& M. Polat (Ed.), Küreselleşme Sürecinde Din Eğitimi Sempozyum Bildiri Kitabı (ss. 37-42). Eskişehir Osmangazi Üniversitesi.

- Gül, A. R. (2017). Açıköğretim Illahiyat Programları: Problemler Ve Çözüm Önerileri. Cumhuriyet illahiyat Dergisi, 21(3), 1905-1940.

- Gümrükçüoğlu, S., \& Genç, M. F. (2020). İlitam Bölümü Öğrencilerinin İlâhiyat Eğitimine Bakışı Kocaeli Üniversitesi İlâhiyat Fakültesi İlitam Örneği. İhya Uluslararası İslam Araştırmaları Dergisi, 6(2), 640-656.

- Güngör, A. (2021). Yükseköğretim Öğrencilerinin ‘Uzaktan Eğitim Kavramına ílişkin Metaforik Algıları: Kilis 7 Aralık Üniversitesi İslami İlimler Fakültesi Örneği. Eskiyeni, 45, 693-717.

- Işıkdoğan, D. (2016). Türkiyede Uzaktan Din Eğitimi. A Grafik Yay.

- Illtuş, C. (2021). Din Eğitiminde Dijital Mecraların Kullanımı. Avrasya Sosyal ve Ekonomi Araştırmaları Dergisi, 8(3), 523-532.

- Karateke, T. (2020a). Açıköğretim İmam Hatip Liselerinde Din Eğitimi. Illahiyat Yay.

- Karateke, T. (2020b). illitam Öğrencilerinin Bu Programı Seçme Nedenleri Ve Karşılaştıkları Sorunlar: Fırat Üniversitesi Örneği. Değerler Eğitimi Dergisi, 18(39), 235-262.

- Kaymakcan, R., Meydan, H., Telli, A., \& Cevherli, K. (2013). Paydaşlarına Göre İlahiyat Lisans Tamamlama (ilitam) Programının Değerlendirilmesi. Değerler Eğitimi Dergisi, 11(26), 71-110.

- Kaymakcan, R., Meydan, H., Telli, A., \& Cevherli, K. (2014). Illahiyat Lisans Tamamlama Programının Verimliliği Üzerine Olgusal Bir Araştırma. Hitit Üniversitesi İlahiyat Fakültesi Dergisi, 13(26), 43-62. 
- Kılıç, Y. (2010). Eş Zamanlı Ve Eş Zamansız Uzaktan Eğitim Ortamlarındaki Çevrimiçi Etkileşimlerin Yapısal Çözümlemesï [Yüksek Lisans Tezi]. Ankara Üniversitesi Eğitim Bilimleri Enstitüsü.

- Kılınç, M. (2015). Uzaktan Eğitim Uygulamalarının Etkililiği Üzerine Bir Araştırma (İnönü Üniversitesi Uzaktan Eğitim Merkezi İlahiyat Lisans Tamamlama Programı Örneği) [Doktora Tezi]. İnönü Üniversitesi Sosyal Bilimler Enstitüsü.

- Kızılabdullah, Y. (2011). Uzaktan Öğrenim ve İlahiyat Alanına Yansımaları: Illahiyat Lisans Tamamlama Programı. İçinde D. Günay \& E. Öztemel (Ed.), Uluslararası Yükseköğretim Kongresi: Yeni Yönelişler ve Sorunlar (C. 2, ss. 1520-1527). Deoemed Yay.

- Koç, A. (2020). Covïd-19 Salgini Sürecinde Illahiyat Fakültesï Öğretmenlik Uygulaması Dersinin Uzaktan Eğitim Yoluyla Yapilmasi: Örnek Bir Uygulama Modeli. Milli Eğitim, 49(1), 851-875.

- Kuzudişli, A. (2013). Din Eğitimi ve Sanal Alem. İçinde H. Aydın \& M. Polat (Ed.), Küreselleşme Sürecinde Din Eğitimi Sempozyum Bildiri Kitabı (ss. 28-36). Eskişehir Osmangazi Üniversitesi.

- Maşaran, B., Yalman, M., \& Erkan, S. (2017). Evaluation of Students' Attitudes Towards E-Exams and Use of Technology in Theology Distance Undergraduate Education Programs. Hitit Üniversitesi Ilahiyat Fakültesi Dergisi, 16(31), 277-299.

- Öncü, A., \& Onulur, T. (2021). Diyanet İşleri Başkanlığının Uzaktan Kur’an Öğretimi Programı Üzerine Nitel Bir Araştırma (Denizli Örneği). Pamukkale Üniversitesi Illahiyat Fakültesi Dergisi, 8(1), 417-443.

- Yazıbaşı, M. A., Yemenici, A., Serinsu, M. E., \& Zengin, Z. S. (2021). Covid-19 Pandemi Sürecinde İlahiyat/ İslami İlimler Fakültesi Öğretim Elemanları Ve Öğrencilerinin Uzaktan Eğitim Sistemi İle İlgili Tecrübelerinin Değerlendirilmesi Üzerine Nicel Bir Araştırma. Ulum Dini Tetkikler Dergisi, 4(1), $231-264$.

- Yiğit, Y. (2021). Öğrencilerin Dijital Ortamlar Üzerinden Yapılan Din Kültürü Ve Ahlak Bilgisi Derslerine Yönelik Tutumları (Sivas Zara İlçesi Örneği). Bingöl Üniversitesi Illahiyat Fakültesi Dergisi, 17, 187-204.

\section{Uzaktan Din Eğitimi Konulu Bilimsel Çalıșmalara Ait Analizler}

Uzaktan din eğitimi konulu bilimsel çalışmaların yayın sıklığı, yayın türü, alan, konu, yöntem açısından analizi bu çalışmanın ana gayesidir. Yapılan analizler, uzaktan din eğitimi hakkında bugüne kadar nelerin yapıldığı ile ilgili bir fotoğrafın çıkmasına yardımcı olacaktır. Bundan sonraki süreçte yapılacak akademik çalışmalar için yol gösterici olacağı düşünülen bu analizler her disiplin için önemli bir hareket noktası olarak kabul edilmektedir.

Tablo 1. Dönemlere Göre Yayın Sıklığı

\begin{tabular}{lcc}
\hline \hline & $f$ & $\%$ \\
\hline $2005-2019$ & 18 & 45,0 \\
$2020-$ & 22 & 55,0 \\
Toplam & 40 & 100,0 \\
\hline \hline
\end{tabular}

Türkiye'de uzaktan din eğitimi konulu bilimsel yayınları yayın sıklığı açısından değerlendirdiğimizde bu süreci üç kısma ayırmak mümkündür. İlki, 1975'ten 2004'e kadar olan dönemdir. Nitekim Türkiye'de ilk kez 1975 'te Yüksek İslam Enstitüleri bünyesinde dışarıdan bitirme programı düzenlenmiştir (Kaya, 2002, s. 32). Bu dönemde yayımlanmıș akademik yayın bulunmamaktadır. Bunda en büyük etkenin Türkiye'de henüz din eğitiminin bilimsel bir disiplin haline gelmemesidir. Ancak 1980 yılında din eğitimi kürsüsünün kurulmasıyla din eğitimi alanı doğmuş oldu (Tosun, 2009, s. 298). 1982 yılında ise din eğitimi ana bilim dalına dönüşüm gerçekleşti (Öcal, 1998, s. 257). İkinci dönem, 2005-2019 arası dönemdir. İkinci dönemin 2005 olarak belirlenmesinin sebebi, bu tarihte illahiyat Lisans Tamamlamanın (ILITAM) illahiyat Fakültesi akademik koordinatörlüğünde faaliyete başlamasıdır (Altaş, 2016, s. 17). Bu dönemde toplam 18 bilimsel yayın gerçekleşmiştir. Ancak bu dönemde de ilk yayınların 2010 yılında başladığı belirlenmiştir. Yani 2010 yılına kadar uzaktan din eğitimi konulu bilimsel yayına rastlanmamıştır. Üçüncü dönem ise dünya genelinde hayatı olumsuz etkileyen Covid-19 sebebiyle uzaktan eğitime geçişin zorunlu hale geldiği 2020 yılından günümüze kadar olan süreçtir. Bu dönemde, yani bir buçuk yıllık süreç içinde, 22 yayının gerçekleştiği görülmektedir. Bu şekilde uzaktan din eğitimi konulu bilimsel yayın sıklığının günümüze yaklaştıkça arttığı tespit edilmiştir. 


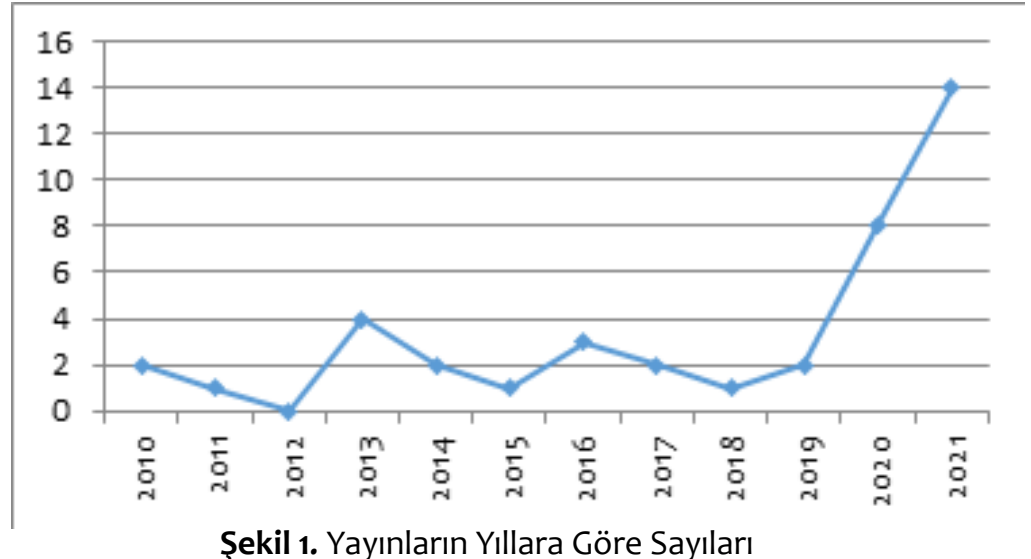

Şekil 1'de görüldüğü gibi Uzaktan din eğitimi hakkında ilk bilimsel çalışma 2010 yılında yapılmıştır. Bu tarihten 2019 yılına kadar 3 yüksek lisans tezi, 1 doktora tezi, 9 makale, 4 bildiri ve 1 kitap çalışması yapılmıștır. 2020 yılından 2021'e kadar 2 yüksek lisans, 18 makale, 1 bildiri ve 1 kitabın yayınlandığı tespit edilmiştir. Bu verilere ait bilgiler tablo 2'de gösterilmiştir. Bilimsel çalışmaların 2019 yılından sonra artış göstermesi yaşanan Covid-19 sürecinde örgün eğitimden uzaktan eğitime zorunlu geçişin yaşanmasından kaynaklandığı düşünülmektedir. Covid-19 sürecinde din eğitimi disiplininin uzaktan eğitime kayıtsız kalmayarak meseleye eğilmesi önemli bir gelişme olarak kabul edilebilir. Covid-19 sürecinde kaleme alınan eserlere bakıldığında daha çok ilahiyat lisans eğitimi ile alakalı yayınların gerçekleştiği buna müteakip dkab eğitimi ile alakalı çalışmaların yapıldığı görülmektedir.

Tablo 2. Dönemlere Göre Yayın Türü Dağılımı

\begin{tabular}{ccccccc}
\hline \hline & \multicolumn{5}{c}{ Yayın Türü } \\
\cline { 2 - 7 } Yüksek Lisans Tezi & $\begin{array}{c}\text { Doktora } \\
\mathrm{f}\end{array}$ & $\begin{array}{c}\text { Maka- } \\
\text { le }\end{array}$ & $\begin{array}{c}\text { Bil- } \\
\text { diri }\end{array}$ & $\begin{array}{c}\text { Ki- } \\
\text { tap }\end{array}$ \\
\cline { 2 - 7 } & $\mathbf{f}$ & $\mathrm{f}$ & $\mathrm{f}$ & $\mathrm{f}$ & \\
\hline \multirow{2}{*}{ Dönem } & $1975-2004$ & 0 & 0 & 0 & 0 & 0 \\
& $2005-2019$ & 3 & 1 & 9 & 4 & 1 \\
& $2020-$ & 2 & 0 & 18 & 1 & 1 \\
& Toplam & $\mathbf{5}$ & $\mathbf{1}$ & $\mathbf{2 7}$ & $\mathbf{5}$ & $\mathbf{2}$ \\
\hline \hline
\end{tabular}

Tablo 2'ye bakıldığında uzaktan din eğitimi hakkındaki bilimsel çalışmaların 27'sinin makale, 5'inin Yüksek Lisans tezi, 5'inin bildiri, 2'sinin kitap ve 1'inin doktora tezi olduğu görülmektedir. Uzaktan din eğitimi konulu bilimsel çalışmaların daha çok makale türünde kaleme alındığı tespit edilmektedir. Konu ile ilgili kitap ve tez çalışmalarının az olması dikkat çekicidir. Uzaktan din eğitimi konulu doktora tezinin alan dışı bir bilim dalına ait olduğu tespit edilmiştir. Uzaktan din eğitim konulu bilimsel çalışmalarda hangi alan üzerinde durulduğu ile ilgili bir analiz yapıldığında daha çok ilitam ile ilgili çalışmanın yapıldığı anlaşılmaktadır. 
Tablo 3. Yayının Yapıldığı Alan ile ilgili Frekans Tablosu

\begin{tabular}{lcc}
\hline \hline Alan & $\mathbf{f}$ & $\%$ \\
\hline Açıköğretim & 1 & 2,5 \\
Illitam & 17 & 42,5 \\
Illahiyat & 8 & 20,0 \\
Dkab & 7 & 17,5 \\
Derleme & 3 & 7,5 \\
Kur’an Öğretimi & 1 & 2,5 \\
DỉB & 2 & 5,0 \\
Online İslami Eğitim & 1 & 2,5 \\
Toplam & $\mathbf{4 0}$ & $\mathbf{1 0 0 , 0}$ \\
\hline \hline
\end{tabular}

Tablo 3 incelendiğinde ilitam ile ilgili 17, ilahiyat lisans eğitimi ile ilgili 8, dkab dersi için 7 bilimsel çalışmanın yapıldığı görülmektedir. Uzaktan din eğitimi konulu 2 derleme yayın, Diyanet İşleri Başkanlığı (DiB) ile ilgili 2, Online İslami eğitim ile ilgili 1 ve açıköğretim ile ilgili 1 yayının olduğu tespit edilmiştir. Uzaktan din eğitimi hakkında bilimsel çalışmaların hangi konular üzerinde durduğu da önemli bir husustur. Bununla ilgili verileri tablo 4'te görmek mümkündür.

Tablo 4. Yayınların konu dağı̆ımı ile ilgili Frekans Tablosu

\begin{tabular}{lcc}
\hline \hline \multicolumn{1}{c}{ Konu } & $\mathbf{f}$ & $\%$ \\
\hline Din Eğitimi ve Dijitalleşme & 2 & 5,0 \\
Din Eğitiminde Medyanın & 1 & $\mathbf{2 , 5}$ \\
Kullanımı & & \\
Çevrim İçi Eğitim & 14 & 35,0 \\
Geçerlik Güvenirlik & 1 & 2,5 \\
Uzaktan Eğitim & 17 & 42,5 \\
E-Sınav & 3 & 7,5 \\
Müfredat & 2 & 5,0 \\
Toplam & $\mathbf{4 0}$ & $\mathbf{1 0 0 , 0}$ \\
\hline
\end{tabular}

Tablo 4'e bakıldığında daha çok uzaktan eğitim ve çevrimiçi eğitim konularında yayının olduğu, ölçme ve değerlendirme ile ilgili 3, müfredat ile ilgili 2 , din eğitimi ve dijitalleşme konusunda 2 , din eğitiminde medyanın kullanımı konusunda 1 ve geçerlik-güvenirlik çalışması ile ilgili 1 yayının olduğu tespit edilmiştir.

Tablo 5. Yayınlarda Kullanılan Yöntemlerin Frekans Dağılımı

\begin{tabular}{lcc}
\hline \hline Yöntem & f & $\%$ \\
\hline Nicel & 14 & 35,0 \\
Nitel & 19 & 47,5 \\
Karma & 7 & 17,5 \\
Toplam & $\mathbf{4 0}$ & $\mathbf{1 0 0 , 0}$ \\
\hline \hline
\end{tabular}

Tablo 5'e göre çalışmaların \% 47,5 'inde nitel araştırma yöntemleri, \%35'inde nicel araştırma yöntemleri ve $\% 17,5^{\prime}$ inde karma yöntemler kullanılmıştır. Çalışmalarda teknik olarak da anket ve görüşme tekniklerinin kullanıldığı anlaşılmaktadır. 


\section{Tartışma ve Sonuç}

Bu çalışmanın amacı Türkiye'de yayımlanan uzaktan din eğitimi konulu bilimsel çalışmalar ile ilgili literatür hakkında bir takım değerlendirme yapmaktır. Uzaktan din eğitimi hakkında yapılan bilimsel çalışmalar yayın sıklığı, alan, konu ve yöntem açısından incelenmiştir.

Araştırmada elde edilen sonuçlara göre uzaktan din eğitimi konulu bilimsel çalışmaların ilk örnekleri 2010 yılında kaleme alınmıştır. Uzaktan din eğitimi konulu bilimsel çalışmaların varlığı din eğitiminin yükseköğretim düzeyindeki uzaktan eğitim ile ilgili uygulamaya yönelik çalışma tarihi ile paralellik göstermektedir. 2010 yılından önce hayata geçirilen Açıköğretim İmam Hatip Okulları ile ilgili daha öncesinde bilimsel çalışmaların yapılmamış olması ve 2010 yılından sonra yapılan uzaktan din eğitimi konulu bilimsel çalışmaların daha çok ilitam ile ilgili olması dikkat çekicidir. Türkiye'de uzaktan eğitim ile ilgili çalışmalara bakııldığında ise ilk bilimsel yayınların 1982 yılından önce 4 eserin kaleme alındığı, Açıöŏgretim Fakültelerinin öğretime başladığı 1982 yılı ile 1992 yılı arasında ise 116 eserin kaleme alındığı tespit edilmiştir. Açıköğretim Liselerinin öğretime başladığı 1992 yilı 2002 yılı arasında 268 bilimsel çalışma gerçekleşmiştir (Demiray \& Terlemez, 2003, s. 58). Genel olarak bakıldığında uzaktan eğitim uygulamalarının başladığı tarihlerde ilk on yıl içerisinde pek çok bilimsel çalışmanın kaleme alındığı görülmektedir. Yine bu çalışmada elde edilen sonuçlardan biri de ilahiyat düzeyinde çalışmaların gerçekleşmiş olmasıdır. Daha sonra dkab alanında bilimsel araştırmaların ele alındığı görülmektedir. ilahiyat ve dkab ile ilgili çalışmaların Covid-19 sürecinde ve öğrencilerle birlikte gerçekleştiği görülmektedir. Uzaktan eğitim ile ilgili çalışmaların büyük çoğunluğunun öğrencilerle birlikte gerçekleştiği yapılan literatür incelemesinde tespit edilmektedir (Babur vd., 2016, s. 133; Horzum vd., 2013, s. 90).

Bu araştırmada en yüksek orandaki yayın türünün $\% 67,5$ oranındaki makaleler olduğu görülmektedir. Konu ile ilgili literatür incelendiğinde uzaktan eğitim ile ilgili ilk bilimsel çalışmalarda da makale ve bildiri oranının diğer yayın türlerine göre daha yüksek olduğu tespit edilmektedir (Demiray \& Terlemez, 2003, s. 55).

Bu araştırmada daha çok çevrim içi eğitim ve uzaktan eğitim konularında çalışmaların gerçekleştiği görülmektedir. Din eğitimi ve dijitalleşme ile ilgili 2, din eğitimi ve medya ile ilgili 1, ölçme değerlendirme ile ilgili 3, müfredat ile ilgili 1 ve ölçek geliştirme ile ilgili 1 yayının olduğu tespit edilmektedir. Literatür incelendiğinde uzaktan eğitim ile ilgili bilimsel çalışmaların üzerinde durduğu konu alanlarının şu şekilde olduğu görülmektedir: Öğrenme-öğretme modelleri, teknoloji, çoklu ortam, çevrim içi öğrenme, eğitim programı, ölçme değerlendirme, öğrenme stratejileri, öğretim tasarımı, iletişim ve mesleki gelişim (Horzum vd., 2013; Sherry, 1996; A. Şimşek vd., 2008, s. 444, 2009, s. 951; Zawacki-Richter vd., 2009). Bozkurt ve arkadaşlarının (2015) yaptığı bir araştırmada en çok çalışılan konuların etkileşim ve iletişim, öğrenen özellikleri ve öğretim tasarımı olduğu ortaya çıkmıştır (Bozkurt vd., 2015, s. 355). Uzaktan eğitim ile ilgili yapılan tezler üzerinde gerçekleştirilen bir literatür analizinde ise ortam çalışmaları, ölçme-değerlendirme, tasarım geliştirme, öğrenme-öğretme yaklaşımları ve model geliştirme konularının yoğunlukla çalışıldığı belirtilmiştir (Aydın vd., 2019, s. 435).

Uzaktan din eğitimi konulu bilimsel çalışmalarda konu seçiminin daha çok konjoktürel gelişmelere göre belirlenmesi dikkat çekicidir. Bu husus, din eğitimi disiplininin konjoktürel gelişmelere karşı bilimsel çaIışmalar konusunda refleks geliştirmesi adına önemli görülebilir. Bunun yanında özellikle öğrenme stratejileri, öğrenme-öğretme modelleri, ölçme değerlendirme, eğitim programı, web tabanlı öğretim, iletişim, mesleki gelişim gibi konuların ele alınmasının alana önemli derecede katkı sunacağı düşünülmektedir.

Bu araştırmada uzaktan din eğitimi konulu çalışmalarda yöntem olarak daha çok nitel yaklaşımın esas alındığı, nicel yöntemin de çoğunlukla kullanıldığı tespit edilirken literatüre bakıldığında nicel yaklaşımın daha çok tercih edildiği görülmektedir (Gökmen vd., 2017, s. 11; Zawacki-Richter vd., 2009). Bernard ve arkadaşları (2004) tarafından yapılan bir çalışmada uzaktan eğitim konulu çalışmalarda kullanılan nicel yöntemlerin istenilen seviyede yayının ortaya çıkmasına katkı sunmadığı vurgulanmıştır (Bernard vd., 2004). Türkiye'de uzaktan eğitim ile ilgili yapılan çalışmalarda daha çok nitel yöntemlerin kullanıldığı görülmektedir (Babur vd., 2016, s. 130; Horzum vd., 2013, s. 90). Bilimsel çalışmaların yöntemsel açıdan irdelenmesi, alana özgü kuramsal temeller oluşturma ve uygulamalar geliştirme imkânı tanır. Bu da uzaktan eğitim sistemlerinin kalitesinin ve işlevselliğinin artmasına yol açacaktır (Gökmen vd., 2017, s. 2).

Yapılan bu çalışmanın sonucunda uzaktan din eğitimi çalışmalarının sayısının azlığı göze çarpmaktadır. Olan çalışmaların da özellikle ilitam ve Covid-19 süreci ile alakalı çalışmalar olduğu tespit edilmektedir. Sonuç itibariyle uzaktan din eğitimi konulu bilimsel çalışmaların uzaktan eğitimin literatürde var olan ve güncel eğilimlerini yakalaması gerektiği ortaya çıkmaktadır. Din eğitimi disiplini için uzaktan eğitimin etkililiğin artması ancak kendine özgü kuramların olması ile sağlanabilir. Uzaktan eğitimin din eğitimi için kullanılabilir bir uygulama alanı olması adına daha çok bilimsel çalışmaların yapılması gerekli görülmektedir. Özellikle uzak- 
tan din eğitimi konulu tezlerin daha çok gerçekleşmesi konu ile ilgili araştırmacıların ilgisini çekeceği tahmin edilmektedir. Açıköğretim İmam Hatip okulları ile alakalı bilimsel çalışmaların yok denecek kadar az olması ve bu okulların yaklaşık 20 yıllık geçmişinin olması konuya dair araştırmaların yapılmasını zaruri kılmaktadır. Yapılacak araştırmaların içeriğe yönelik ve karşılaştırmalı değerlendirme bazlı olması gerekliliği gözlenmektedir. Uzaktan din eğitimi ve uygulamaları ile ilgili bilimsel çalışmaların çeşitlenmesi için araştırmacıların teşvik edilmesi gerekliliği öne çıkmaktadır. Bunlarla uzaktan din eğitiminin tüm saha ve kademelerdeki kalitesinin artması beklenmektedir.

\section{Kaynakça}

Altaş, N. (2016). Türkiye'de dinî yükseköğretim alanında uzaktan eğitimle ilgili algı sorunları ve íLiTAM uygulamaları. Değerler Eğitimi Dergisi, 14(31), 7-41.

Armaner, N. (1967). Inanç ve hareket bütünlüğü bakımından din terbiyesi. Ankara : Milli Eğitim Bakanlığı.

Aşıkoğlu, N. Y. (1994). Din eğitimi biliminin Türkiye'de bağımsız bir bilimsel disiplin olarak doğuşu ve gelişimi. Diyanet IImi Dergi, 30(3), 85-92.

Aydın, i. E., Kaya, S., İşkol, S., \& İşcan, A. (2019). Anadolu Üniversitesi Uzaktan Eğitim bölümünde yayınlanmış yüksek lisans ve doktora tezlerinin içerik analizi. Yükseköğretim ve Bilim Dergisi, 3, 430-441.

Ayhan, H. (1997). Din eğitim ve öğretimi. İfav Yay.

Babur, A., Kiper, A., Çukurbaşı, B., Özer, E. A., Tonbuloğlu, I., Küçük, Ş., Demirhan, E., Güngören, Ö. C., Kıyıcı, M., \& Horzum, M. B. (2016). 2009-2013 Yılları arasında uzaktan eğitim dergilerinde yayınlanan makalelerin yöntemsel açıdan incelenmesi. Sakarya University Journal of Education, 6(1), 123-140.

Bernard, R., Abrami, P., Lou, Y., \& Borokhovski, E. (2004). A methodological morass? How we can improve quantitative research in distance education. Distance Education, 25(2), 175-198.

Bozkurt, A., Akgun-Ozbek, E., Yilmazel, S., Erdogdu, E., Ucar, H., Guler, E., Sezgin, S., Karadeniz, A., Sen-Ersoy, N., \& Goksel-Canbek, N. (2015). Trends in distance education research: A content analysis of journals 2009-2013. International Review of Research in Open and Distributed Learning, 16(1), 330-363.

Broadbent, J. A., \& Cross, N. (2003). Design education in the information age. Journal of Engineering Design, 14(4), 439-446.

Cevizci, A. (1999). Felsefe sözlüğü. İstanbul : Paradigma Yayınları.

Demiray, U., \& Terlemez, M. S. (2003). Açıkögretim Fakültesi ve Açıkögretim Lisesi uygulamalarını içeren araştırmalara ilişkin bir değerlendirme. TOJET: The Turkish Online Journal of Educational Technology, 2(4).

Erden, M. (1998). Öğretmenlik mesleğine giriş. Alkın Yay.

Foulquie, P. (1994). Pedagoji sözlüğü (C. Karakaya, Çev.). Sosyal Yay.

Furat, A. Z. (2019). Din eğitimi ekseninde Türkiye'de medya ve din araştırmaları. Medya ve Din Araştırmaları Dergisi, 2(1), 29-51.

Gökmen, Ö. F., Uysal, M., Yaşar, H., Kırksekiz, A., Güvendi, G. M., \& Horzum, M. B. (2017). Türkiye'de 2005-2014 yılları arasında yayınlanan uzaktan eğitim tezlerindeki yöntemsel eğilimler: Bir içerik analizi. Eğitim ve Bilim, 42(189), 1-25.

Gözütok, Ş. (2013). E-öğrenme ve yeni öğrenme ortamları. içinde H. Aydın \& M. Polat (Ed.), Küreselleşme Sürecinde Din Eğitimi Sempozyum Bildiri Kitabı (ss. 37-42). Eskişehir Osmangazi Üniversitesi.

Holmberg, B. (1990). Perspectives of research on distance education. FemUniversitat.

Horzum, M. B., Özkaya, M., Demirci, M., \& Alpaslan, M. (2013). Türkçe uzaktan eğitim araştırmalarının incelenmesi. İnönü Üniversitesi Eğitim Fakültesi Dergisi, 14(2), 79-100.

Karateke, T. (2020). Açıöğretim Imam Hatip Liselerinde din eğitimi. ilahiyat Yay.

Kaya, Z. (2002). Uzaktan eğitim. Pegem A.

Kayadibi, F., Furat, A. Z., \& Başkurt, i. (2008). ilahiyat Fakülteleri dergilerinde yayımlanan din eğitimi konulu makaleler üzerine bir değerlendirme. İstanbul Üniversitesi İlahiyat Fakültesi Dergisi. 
Kaymakcan, R., \& Unsal, B. (2004). illahiyat Fakülteleri dergilerinde yayımlanan din eğitimi konulu makaleler üzerine bir değerlendirme. Değerler Eğitimi Dergisi, 2(6), 51-76.

Kılıç, D. (2006). Eğitim bilimlerine giriş. Aydan Matbaacılık.

Kızılabdullah, Y. (2009). İlahiyat Fakültelerinin kuruluşundan bugüne din eğitimi bilimi alanında yapılan çalışmalar üzerine bir değerlendirme. Türk Bilimsel Derlemeler Dergisi, 2(1), 305-314.

Koşar, E., Yüksel, S., Özkılıç, R., Avcı, U., Alyaz, Y., \& Çiğdem, H. (2003). Öğretim teknolojileri ve materyal geliştirme. Öğreti-Pegem A.

Moore, M. G. (1973). Toward a theory of independent learning and teaching. Journal of Higher Education, 44(12), 661-679.

Moore, M. G., \& Kearsley, G. G. (2005). Distance education: A system view. Wadsworth.

Öcal, M. (1998). Cumhuriyet döneminde Türkiye'de din eğitimi ve öğretimi. Uludağ Üniversitesi Illahiyat Fakültesi Dergisi, 7(7), 241-268.

Öcal, M. (2008). Türkiyesde din eğitimi tarihi literatürü. Türkiye Araştırmaları Literatür Dergisi, 12, 399-430.

Selçuk, M. (1990). Çocuğun eğitiminde dini motifler. Türkiye Diyanet Vakfı Yayınları.

Senemoğlu, N. (2004). Gelişim, öğrenme ve öğretim. Gazi Kitabevi.

Sherry, L. (1996). Issues in distance learning. International Journal of Distance Education, 1(4), 337-365.

Şimşek, A., Özdamar, N., Becit, G., Kılıçer, K., Akbulut, Y., \& Yıldırım, Y. (2008). Türkiye'deki eğitim teknolojisi araştirmalarında güncel eğilimler. Selçuk Üniversitesi Sosyal Bilimler Enstitüsü Dergisi, 19, 439-458.

Şimşek, A., Özdamar, N., Uysal, Ö., Kobak, K., Berk, C., Kılıçer, T., \& Çiğdem, H. (2009). Türkiye'deki eğitim teknolojisi araştırmalarında gözlenen eğilimler. Kuram ve Uygulamada Eğitim Bilimleri Dergisi, 9(2), 115-120.

Şimşek, H., \& Yıldırım, A. (2008). Sosyal bilimlerde nitel araştırma yöntemleri. Seçkin Yayınları.

Tosun, C. (2009). Bir anabilim dalı olarak Türkiye'de din eğitiminin doğuşu, gelişmesi ve alanına katkıları. Türk Bilimsel Derlemeler Dergisi, 2(1), 293-303.

Varış, F. (1981). Eğitim bilimine giriş. Ankara : Ankara Üniversitesi Eğitim Fakültesi.

Verduin, J., \& Clark, T. (1994). Uzaktan eğitim: Etkin uygulama esasları (i. Maviş, Çev.). Anadolu Üniversitesi Basımevi.

Yavuz, K. (1998). Günümüzde din eğitimi. Çukurova Üniversitesi İlahiyat Fakültesi Yay.

Zawacki-Richter, O., Bäcker, E. M., \& Vogt, S. (2009). Review of distance education research (2000 to 2008): Analysis of Research Areas, Methods, and Authorship Patterns. International Review of Research in Open and Distributed Learning, 10(6), 21-50. 


\title{
MEDIAD
}

\section{A Review on Academic Studies About Distance Religious Education}

\author{
Veysel Karani ALTUN
}

\section{Extended Abstract}

An educated person is defined as a person who knows access to information and can make sense of the information he reaches. Access to information has become much easier today with technological developments. In the information society, education is evaluated as an activity carried out with flexible systems. Technological developments have always accelerated the sociocultural change of human beings. It is seen that education gradually changes its face with the effect of new communication technologies when evaluated in terms of today.

With technological developments, the concept of Distance Education has become more used in the education process; because through distance education, it becomes possible for education to find the prevalence and occur in less time. In this case, it has also become debatable whether Distance Education replaces the true function of Education. Although distance education seems to provide convenience to a person in terms of space and time compared to face-to-face education, it is important to understand and internalize it as well as to access information. However, some natural events such as today's astonishing communicative advances and epidemics that affect the whole world make distance education compulsory. Distance education can be defined as the gathering of individuals who are in different places through mass media and carrying out educational activities simultaneously or asynchronously. Synchronization and realization in the same place, which are traditional education conditions, are not in question in distance education, so it allows learners and teachers to use their time in this regard and make the activity economical.

It is thought that distance education practices have continued their existence as a part of education since ancient times. Distance education, which started with the correspondence of philosophers in the early ages, has passed through many stages over time with the development of technology and mass media. It is possible to come across the first examples of distance education when looking at the history of Islamic education. For example, the concepts of ratification and tractate have continued to exist as a teaching method in the history of Islamic education for a long time and laid the groundwork for the emergence of genres and different educational methods. Ratification, which emerged as an experience peculiar to the tradition of Islamic education and training, is the term that expresses the time, type, and level of science, knowledge, art, and vocational education, and the necessary permission and approval document for competencies in these fields. Recently, traditional mass media have been replaced by an informatics-based computer communication network. In particular, it is possible to say that the internet fulfills all the functions of other media more easily, quickly, and smoothly. While the benefits of distance education such as equality of opportunity, offering different education options, facilitating education, reducing costs, increasing quality, providing individual and independent learning, and giving the individual the responsibility of learning, some limitations are also mentioned.

The problem of this study is related to the current situation of studies on distance religious education in Turkey. This study aims to take a picture of studies on distance religious education.

This study is descriptive research based on document review and content analysis. In the literature review method, previous theoretical and empirical studies related to the problem are determined by reviewing the literature, and their contents and results are briefly explained. The literature review method was used as the method of our study. In the literature review method, previous theoretical and empirical studies related to the problem are determined by reviewing the literature, and their contents and results are briefly explained. In the first part of our study, information about distance education was given. In the following chapters, what is distance religious education is mentioned and examples of its application methods are given. 
In this study, distance education is examined both conceptually and as a form of practice. However, distance religious education is also considered both conceptually and practically. The aim of this study, in which the steps taken towards distance education in Turkey and the current situation of distance education are discussed, is to reveal what kind of approach is exhibited to distance education in Turkey and worldwide.

It is known that the traditional concepts and traditional approaches in the field of education have undergone radical changes and transformations in today's world, where mass media are effectively used in our lives along with information and technological developments. One area where this change and transformation will take place in the field of religious education and training. Instead of unplanned, unscheduled religious activities organized by using the power of the media, planned and systematic education and training activities for the society make their presence felt like an important need.

\section{Araştırmacıların Katkı Oranı Beyanı/ Contribution of Authors}

Araştırma tek bir yazar tarafından yürütülmüştür.

The research was conducted by a single author.

$$
* * * * * * * *
$$

\section{Çıkar Çatışması Beyanı / Conflict of Interest}

Çalışma kapsamında herhangi bir kurum veya kişi ile çıkar çatışması bulunmamaktadır.

There is no conflict of interest with any institution or person within the scope of the study.

$* * * * * * * *$

Intihal Politikası Beyanı / Plagiarism Policy

Bu makale iThenticate yazılımıyla taranmıştır. İntihal tespit edilmemiştir.

This article has been scanned by iThenticate. No plagiarism was detected.

$* * * * * * * *$

Bilimsel Araştırma ve Yayın Etiği Beyanı / Scientific Research and Publication Ethics Statement

Bu çalışmada “Yükseköğretim Kurumları Bilimsel Araştırma ve Yayın Etiği Yönergesi” kapsamında uyulması belirtilen kurallara uyulmuştur.

In this study, the rules stated in the "Higher Education Institutions Scientific Research and Publication Ethics Directive" were followed 